\title{
Exploring (Inter)Subjectivity and Constructional Changes
}

\author{
Xu Yang \\ School of International Studies, Southwest University, Chongqing, China \\ Email: byyangxu@sina.com \\ Received 22 May 2015; accepted 21 June 2015; published 24 June 2015 \\ Copyright (c) 2015 by author and Scientific Research Publishing Inc. \\ This work is licensed under the Creative Commons Attribution International License (CC BY). \\ http://creativecommons.org/licenses/by/4.0/ \\ (c) () Open Access
}

\begin{abstract}
Subjectivity is a property of language and it concerns speaker's expressions of his own evaluation and his imprint shown in an utterance. Inter subjectivity is a derivational form of subjectivity, implicating the speaker's recognition to the addressee and paying attention to the needs of an addressee's face and self-image. Subjectivity can prompt the constructional change and bring about constructionalization. This research probes into the politeness realization in daily expressions and proposes that (inter)subjectivity is closely connected with constructional change. Subjectification can be regarded as one of main factors which bring about constructionalization.
\end{abstract}

Keywords

(Inter)Subjectivity, Constructional Change, Constructionalization

\section{Introduction}

Subjectivity is regarded as a sense of self-awareness without something unverifiable. Traugott employs a diachronic perspective to combine the study of subjectivisation with grammaticalisation. Subjectivity has been explored in semantics at least since Breal (1964) [1]. The significance of subjectivity was emphasized by Benveniste (1971: p. 226) [2]:

It is in the instance of discourse in which I designate the speaker that the speaker proclaims himself as the "subject". And so it is literally true that the basis of subjectivity is in the exercise of language...Language is so organized that it permits each speaker to appropriate to himself an entire language by designating himself as I.

According to Lyon (1982:102) [3], subjectivity refers to the way in which natural languages in their structure and their normal manner of operation provide for the locutionary agent's expression of himself and its own attitudes and beliefs. Finegan (1992) [4] states that subjectivity concerns the participation and involvement in the discourse, that's to say, about the linguistic expression of self. And language is not solely as form nor just as the 
expression of propositional neither thought, nor as autonomous structure nor as representing logical propositions, but as a kind of expression of perceiving and feeling.

Langacker and Traugott are the most prominent figures in this field. They characterize grammaticalisation as a unidirectional process involving subjectification. Based on Carey's distinction (1992) [5], Traugott (2003) [6] emphasizes the role of subjectification and regards it as a process in a form or construction that serves an objective function comes to encode more speaker-based, discourse functions. In contrast, Langacker's notion emphasizes the role of construal: some aspects of here-and-now of the speech event can be construed with a lesser or greater degree of subjectivity; the lower the level of awareness, the more subjective the construal. This research make a brief review about Langacker and Traugott's notions on subjectivity at first, then probes into the politeness realization in daily expression, and finally provides a new perspective for constructional change.

\section{Subjectivity, Subjectification, and Intersubjectivity}

\subsection{Langacker's Views on Subjectivity}

Undoubtedly, Langacker's studies contribute tremendously to the development of subjectivity. Unlike Traugott, Langacker does not concern himself with the details of the process of semantic change, and also does not specify where the change first occurred (Carey, 1992) [5], and in this sense, his works on subjectivity mainly dwell on a synchronic perspective. Traugott (1992) [4] summarizes that Langcker's work focuses on a gradient phenomenon which is found synchronically and concerns degrees of grounding in the perspective of the speaker from a cognitive point of view. It is the participant in the speech who construes all situations. The most prominent synchronic examples of the gradience are listed by Langacker (1990: pp. 17-20) [7]:

(1) a. Vanessa jumped across the table.

$b$. Vanessa is sitting across the table from Veronica.

c. Vanessa is sitting across the table from me.

d. Vanessa is sitting across the table.

According to Langacker, the preposition across in (1a) is maximally objective with its motion profiled without concerning the speaker-hearer's position. Compared to (1a), (1b, 1c) are more subjective in that across represents not concrete motion, but the abstract construal of the speaker tracing a mental path in order to locate the reference point. (1d) is the most subjective among the all because the referent point is identified with the speaker (Traugott, 1992) [4].

\subsection{Traugott's Views on Subjectivity and Intersubjectivity}

Generally speaking, subjectivity manifests the speaker's expression, viewpoint and attitude in discourse. It is also called a speaker's imprint. In turn, subjectification refers to the structures and strategies that language evolves in the linguistic realization of subjectivity or to the relevant processes of linguistic evolution themselves (Finegan, 1992) [8]. This evolution results in new type nodes. This is costructionalization theory proposed byTraugott and Trousdale (2013) [9].

Traugott attempts to explore subjectification in grammaticalization, and her works are mostly centered on subjectification in grammaticalization in a diachronic way. Traugott (1989) [10] defines subjectification in a pragmatic-semantic context, that is, a process whereby the grasp of the meaning in an utterance become more and more inclined to addresser or speaker's subjective beliefs or attitudes towards the proposition.

It was Benveniste's (1971) [2] landmark paper that distinguished subjectivity and intersubjectivty from a synchronic perspective. Traugott conceives subjectivity as a relationship to the speaker and speaker's belief, even to the addresser and addressee's face. She adopts Lyon's some ideas about subjectivity and makes a fresh distinction between subjectivity and subjectification (Traugott, 2003) [6]. She argues that expressions of subjectivity and intersubjectivity are the prime semantic or pragmatic of which index speaker's attitude or viewpoint (subjectivity) and speaker's attention to addressee self-image (intersubjectivty).

These examples are listed to understand the distinctions and their correlations among subjectivity, subjectification, and intersubjectivity:

(2) a. Let us go, will you?

b. Let's go, shall we?

c. Let's take our pills now, Johnny. 
In (2) a-b, it is a process of subjectification, let's indicates the involvement of the speaker himself, which promotes the emotive meaning of the utterance. The process of (2) b-c is a kind of intersubjectification. It shows a sincere consideration of the addressee, but (2) c doesn't suggest that the speaker's action of having the pills, however, the intention of the speaker is to establish a harmonious, intimate relationship with the addressee.

Traugott \& Dasher (2002) [11] suggest that subjectification and intersubjectification are the mechanisms by which meaning are recruited to encode and regulatespeakers' attitudes and beliefs, that is subjectification, and once subjectified, meaning may be engaged in encoding meaning centered on the addressee, that is intersubjectification. This process may come about constructional change and can be described by the following cline (Traugott):

1) Non-/less subjective $>$ subjective $>$ intersubjective.

And then a new cline generated heuristically,

2) Non-/less subjectivized > subjectivized > intersubjectivized.

In case of discourse marker, for example, (as) you see, (as) you know, as far as I am concerned, etc. Fitzmaurice (2004) [12] suggests that there seems to be a further development from intersubjective to interactive, and she develops a hypothesis that there is a shift away from attention to the addressee to simply keeping things going in a conversation, and grabbing the interlocutor's attention. Therefore, the discourse marker shares with new constructional meaning.

\section{An Embodiment of Subjectivity and Intersubjectivity in Euphemism}

Euphemism is rich in almost every language and is a form of substitutive use of language using a less offensive, pleasant word to some appropriate counterparts. According to Rawson (1981) [13], euphemism has very serious reasons for being. To begin with, it conceals the things that people fear the most-death, the dead and the supernatural. Next, it covers up the facts of life of sex and reproduction and excretion-which inevitably remind even the most refined people that they are made of clay, or even worse. In addition, such euphemism is beloved by individuals and institutions (government, especially) who are anxious to present only the handsomest possible images of themselves to the world.

A discussion of the Lord's reference of god, and one of the polysemous uses of pass to denote die, and so on. Some situational use of euphemisms in communication will be explored how the utterance demonstrates the speaker' awareness of the addressee's attitudes and beliefs, especially their face or self-image and a further step to analyze how does subjectivity or intersubjectivity function in the process of politeness.

\subsection{Doctor to Patient Dialogue}

Language is the medium to manifest someone's thoughts or feelings, thus language is the tool to express emotions of human. Doctors must learn the technique to converse and to deal with the human relations. A lack of sympathy should be considered to be a skill inadequacy and a sign of incompetence. It is clear that doctor-patient dialogue is very important. It will directly affect curative effect. And the communication between doctors and patients is characterized by language communication.

In medical discourse, doctors should use some less offensive words by virtue of a substitution of these circumstance taboos, hereby face and feelings of the patients should be taken into consideration. The following examples are elaborated.

Conversation one:

Patient: Nurse! I need your help!

Nurse: Okay, number one or number two?

Patient: Number one.

\section{Conversation two:}

Doctor: Take the red pills 3 times a day, and without communicating.

Patient: Communicate? You mean that it is contagious?

Doctor: No, I mean no sex recently.

In the above two conversations, maybe it takes pains to understand if you didn't have the experiences, piss and dung are always considered to be offensive to apply, so they are delicately avoided by using number one and number two to instead respectively. And when the doctor asks the patient something concerning sexual intercourse, always employs a polysemous of communicate in order not to offend the patient, especially for a female 
addressee, such taboo words tend to make the addressee disgraceful and a negative effect. In Chinese we use 同 房 tongfang or 房事 fangshi to represent the same thing. A selective use of polysemies here is a process of intersubjectification. The use of number one, number two and communicate transcends its ordinary meaning and adds their affective meaning. From a diachronic view, this process of intersubjectification is similar to constructional change. Intersubjectification is considered as the motivation of constructionalization.

\subsection{Death Euphemism}

Death, as well as living, as a necessary pair, accompanies every mortal so far as he or she is on the earth. The deep love to life strengthens the deep fear of death, or vice versa. Hence, the prettying up of death and dying becomes a linguistic necessity in a civilized emotional community or society. People may delicately choose the less offensive ones by virtue of a harmless euphemism, for example, pass way/gone for die, a poetic metaphor like sleep or rest in place of dying. The following is a piece of pleasant description of death:

The loved ones are under the good care of the kind bereavement counselor, after an everlasting cosmetics by the derrma surgeon, they wear a slumber robe, and will be put in a slumber box, then carried to a final resting place, i.e. a memorial, and terminally go to the happy hunting grounds. To die here sounds not so horrible; on the contrary, it is fantastic and exciting like a perfect journey to enjoy oneself.

According to different situations, Death euphemism can be classified into positive euphemism and negative ones. As to positive euphemism, we can easily list many fancy occupational titles, which salve the egos of workers by elevating their job status. Death euphemism is kind of metaphor. Metaphor is a mapping process which is a mapping from source domain to target domain. This process better reflects the (inter)subjectivity from the speaker and the hearer. The classic examples here will be morticians or the aforementioned bereavement counselor or derma surgeon. Besides, the so-called morticians refer to corpses as cases or even patients, and there is no strange understanding on seeing that an mortician asks delicately where to ship the loved ones (Rawson, 1981) [13].

The negative euphemism, also can be called a defensive euphemism. It refers to the using a flattering, pleasant or euphemism reference to take place of the supernatural being's true name. As it is mentioned earlier, the loved one for the death, it is almost the same of using the Lord or Himself to represent saint God.

The following are the euphemisms of death:

1) A formal use

To depart

Happy land

To leave this world

To rest in peace

The final departure

To return to dust

To go to west

To have found rest

2) A humoristic use

To be called home

To be home and free

Final sleep

To sleep

To go to one's long home

To do one's bit

To pay one's fee

To breathe one's last

To shut up the shop

To kick off

To be free

To cancel one's account

Pay one's last debt

3) A proverbial use

To be asleep in the Arms of God 
To be called to God

The call of God

With God

With their Father

To pass away

To kick the bucket

Of course, the list of euphemism of death is numerous, but what does this function? Look at the following dialogue between a newly dead person's spouse and a neighbor:

Neighbor: Mrs Smith, I'm sorry to hear the unhappy news about your husband!

Smith: He is gone in a hurry without leaving any words only leaving us permanent sadness.

...continuing to cry...

Now, let's see a pair of totally different response,

Response One:

Neighbor: Take it easy, don't be so sad! The dead person will never be back no matter how sad you are, every person's destined to death, he just has gone earlier than you!

Response Two:

Neighbor: Take it easy, He just received the call of the God, and he is now on the way to heaven, as a devout Christian, we should under the wills of the God, right? Please believe the kindness God can take good care of him.

From the conversation above, it is a set of reassuring comforts after a death. The response one and two may have distinct functions. For a spouse of a dead, may he/she be in great sorrow, and a frequent mentions the word dead is unpleasant to the spouse of the death. Therefore, an avoidance of immediate reference of such words is essential. From this point of view, Response one is not so successful without considering too much of the addressee. On the contrary, in Response two, by considerate use of substitution of these words related to death. The use of the call of the God, be with God, and heaven to illustrate death, and also with full considering the religious belief of Mrs Smith, it seems that the death is predetermined arrangement of the God and as a devout Christian, God is saint, and Christian should be obedient to the God. In this process, 见上帝 meeting with the God in Chinese indicates death. The neighbor uses the name of the God to persuade the woman without doubt a perfect way. It concerns the feeling and immediate attitudes which called forth from the addressee and thus adds the intimacy and harmony of the utterance. Response one and Response two are correlated with interactive and interpersonal functions in the conversation.

The oriental culture is reluctant to mention death directly. Thus, it is expressed by various indirect, evasive and vague euphemisms to substitute the death expressions. Owning to the richness and diversity of Chinese culture, death euphemisms abound in Chinese. Chinese death euphemisms are more complicated due to their deep cultural connotations; for instance, Chinese death euphemisms can indicate the religious belief, social statue, identities and characteristics of the dead and disclose the speaker's relationship with the dead. Therefore, it is a process of (inter) subjectification. This (inter) subjectification prompts for constructional change because metaphor and metonymy function for the sake of the need of successful communications.

\section{Conclusion}

Subjectivity involves speakers' attitude and beliefs while intersubjectivity concerns addresser and addressee's face. Some (inter)subjectified polite expressions can propel constructional change in the process of communication. (Inter)Subjectivity is closely connected with constructional change. Subjectification can be regarded as one of main factors which bring about constructionalization.

\section{Acknowledgements}

This paper is financed by the Project of Doctors' Innovation for Scientific Research in Chongqing Education Commission. No. CYB14063.

\section{References}

[1] Breal, M. (1964) Semantics: Studies in the Science of Meaning (Trans. by Henry Crust). Dover, New York.

[2] Benveniste, E. (1971) Subjectivity in Language. In: Meek, M. E., Trans., Problems in General Linguistics, University 
of Miami Press, Coral Gables, 223-230.

[3] Lyon, J. (1982) Deixis and Subjectivity: Loquor, Ergo Sum? In: Robert, J. and Klein, W., Eds., Speech, Place, and Action: Studies in Deixis and Related Topics, Wiley, New York, 101-124.

[4] Traugott, E.C. (1992) Subjectification in Grammaticalisation. In: Stein, D. and Wright, S, Eds., Subjectivity and Subjectivisation, Cambridge University Press, Cambridge, 31-54.

[5] Carey, K. (1992) Subjectification and the Development of the English Perfect. In: Stein, D. and Wright, S, Eds., Subjectivity and Subjectivisation, Cambridge University Press, Cambridge, 83-102.

[6] Traugott, E.C. (2003) From Subjectification to Intersubjectification. In: Hickey, R., Ed., Motives for Language Change, Cambridge University Press, Cambridge, 124-139.

[7] Langacker (1990) Concept, Image, and Symbol: The Cognitive Basis of Grammar. Mouton de Gruyter, Berlin.

[8] Finegan, E. (1992) Subjectivity and Subjectivisation: An Introduction. In: Stein, D. and Wright, S., Eds., Subjectivity and Subjectivisation, Cambridge University Press, Cambridge, 1-14. http://dx.doi.org/10.1177/1461445604046585

[9] Traugott, E.C. and Trousdale, G. (2013) Constructionalization and Constructional Changes. Oxford University Press, Oxford. http://dx.doi.org/10.1093/acprof:0so/9780199679898.001.0001

[10] Traugott, E.C. (1989) On the Rise of Epistemic Meaning in English: An Example of Subjectification in Semantic Change. Language, 65, 31-55. http://dx.doi.org/10.2307/414841

[11] Traugott, E.C. and Dasher, R.B. (2002) Regularity in Semantic Change. Cambridge University Press, Cambridge.

[12] Fitzmaurice, S. (2004) Subjectivity, Intersubjectivity, and the Historical Construction of Interlocutor Stance: From Stance Markers to Discourse Markers. Discourse Studies, 6, 427-448.

[13] Rawson (1981) A Dictionary of Euphemism and Other Doubletalk. Crown Publishers, New York. 